\title{
The European Community Respiratory Health Survey II
}

\author{
The European Community Respiratory Health Survey II Steering Committee
}

\begin{abstract}
The European Community Respiratory Health Survey II. The European Community Respiratory Health Survey Steering Committee. (C) ERS Journals Ltd 2002.

ABSTRACT: The European Community Respiratory Health Survey (ECRHS) II will determine the incidence of and risk factors for the development of allergic disease, atopy and rapid loss of lung function in middle-aged adults living in Europe.

From 1991-1993, >18,000 individuals took part in ECRHS I and provided information on symptoms and exposure to known or suspected risk factors for asthma. Blood samples for assessment of specific immunoglobulin $E$ to environmental allergen were taken and lung function and bronchial responsiveness to methacholine were assessed. From 1999-2001, study participants were re-contacted to determine symptom status and exposure to a variety of factors, including tobacco smoke, animals, occupational agents and air pollutants (including particulate matter). In a subsample of responders, exposure to house dust-mite allergen was assessed by analysis of dust samples taken from participants' mattresses. In addition, blood samples suitable for deoxyribonucleic acid extraction were collected and stored.

Currently, European Community Respiratory Health Survey II is being conducted in 29 centres in 14 countries. At the time of writing this paper, 27 centres had begun the study and $\sim 12,000$ participants had completed a short postal questionnaire, $\sim 9,000$ had completed a more detailed health assessment and 3,500 participants had provided dust samples. Historical air-pollution data have been collated and the programme of monitoring particles with a $50 \%$ cut-off aerodynamic diameter of $2.5 \mu \mathrm{m}$ has been completed in 21 centres in 10 countries.

Eur Respir J 2002; 20: 1071-1079.
\end{abstract}

\author{
Correspondence: D. Jarvis \\ Dept Public Health Sciences \\ King's College London \\ 5 th Floor \\ Capital House \\ 42 Weston Street \\ London \\ SE1 3QD \\ Fax: 442078486605 \\ E-mail: deborah.jarvis@kcl.ac.uk \\ Keywords: Asthma \\ atopy \\ cohort \\ epidemiology \\ European Community Respiratory \\ Health Survey \\ forced expiratory volume in one second
}

Received: May 312002

Accepted after revision: June 282002
Diseases associated with allergy and poor lung function contribute substantially to morbidity and mortality in adults living in the developed world. It is well established that the prevalence of asthma, hay fever and eczema has increased substantially over the past $50 \mathrm{yrs}$, although the reasons for the increase are unknown. Whilst it is recognised that the incidence of these conditions is greater in children than in adults, some people will develop them for the first time during their adult life. Adults are exposed to a range of lifestyle and environmental factors that have been suggested to cause allergic disease and rapid loss of lung function, but the extent to which these exposures explain the incidence of these conditions in adults is largely unknown. Cohort studies are the most appropriate design to address these issues, but by their very nature, are expensive to conduct and slow to produce results.

Previous studies provide varying estimates of the incidence of asthma in adults depending on the case definition and case ascertainment methods used [1-3]. The geographical variation in the prevalence of asthma [4] may to some extent be explained by variation in the incidence of adult asthma or in the prognosis of childhood asthma, but a standardised methodology is required to test these hypotheses. Risk factors for adult-onset asthma include sex [3], other allergic diseases, particularly rhinitis $[2,3,5]$, sensitisation to allergens $[2,6]$, exposure to hormonal replacement therapy [7] and workplace exposures [8]. The role of smoking remains contentious, with some studies reporting an association with asthma and wheeze [3,9] whilst others did not observe this association [10]. The incidence of and risk factors for development of sensitisation to environmental allergens in adults is unknown, although one report suggests that older adults who are "atopic" are more likely to become "nonatopic" than those who are younger [11]. Remission of asthma symptoms has been reported in adults [3,12], but it is more common in individuals with mild disease. It is not known whether any other environmental or lifestyle factors are important or whether loss or amelioration of symptoms reflects change in atopic status.

Decline in lung function is an important predictor of overall mortality in the general population [13-15]. Substantial variation in lung function has been reported across Europe [16] but it is not known whether this reflects variation in lung development during childhood, maximal achieved forced expiratory volume in one second (FEV1) or lung function decline in adulthood. Smoking, bronchial responsiveness (BR) [17] and atopy [18, 19] are associated with greater lung function decline but the effect of exposure to allergens is still uncertain [20]. Public health interventions to reduce tobacco consumption and involuntary exposure to tobacco smoke remain the cornerstone of improving respiratory health and lung 
function within populations but other modifiable environmental exposures may also require control. There is emerging evidence that particulate pollution also contributes to lung function decline $[21,22]$ and further information on the strength of this association across differing populations is required to inform appropriate public health policy.

Some population subgroups may be more likely to develop allergic disease or rapid decline in lung function in response to exposure to environmental factors. Susceptibility may be related to genetic makeup or be defined by other physiological or clinical characteristics such as clinical disease, BR or atopy. For example, a substantial proportion of young adults who are sensitised to house dust mite have no overt clinical disease. It is uncertain whether these individuals will experience greater decline in lung function or a greater risk of developing symptoms as they grow older, if they are chronically exposed to high levels of dust mite within their homes compared to those who are not sensitised.

People with asthma who have low lung function are highly symptomatic and have a poor quality of life. The aim of therapy, the mainstay of which is regular daily use of inhaled steroids, is to reduce symptoms and improve lung function by decreasing airway inflammation. These are effective treatments [23, 24] but the extent to which their regular use prevents decline in FEV1 over a prolonged period of time is unknown and the extent to which these treatments modify the influence of other risk factors, such as smoking, BR and atopy [25], on disease progression is uncertain.

From 1991-1993, the European Community Respiratory Health Survey (ECRHS) I studied $>18,000$ young adults from $>35$ centres (predominantly, but not exclusively, in Europe), collecting information on health status and a variety of factors known or hypothesised to be associated with the risk of developing asthma and atopy $[26,27]$. A review of the main results from ECRHS I has been published recently [27].

Many of the research teams who took part in this initial research effort have agreed to continue their collaboration by re-examining participants in ECRHS I. This cohort study, which is currently underway, is known as ECRHS II.

\section{Aim}

The stated aims of ECRHS II are to: 1) determine the incidence and prognosis of allergy, allergic disease (asthma, hay fever and eczema) and low lung function in adults; 2) describe the distribution of exposure to known or suspected environmental risk factors associated with the incidence and prognosis of allergy, allergic disease and low lung function; 3) determine the risk attributable to chronic exposure to these environmental risk factors for the incidence and prognosis of allergy, allergic disease and low lung function; 4) identify subgroups within the population based on sex, prior disease status, BR and genetic risk who may be more susceptible to these environmental risk factors and measure their excess risk; and 5) establish a bank of blood samples suitable for deoxyribonucleic acid (DNA) extraction taken from representative samples of the population that can be linked to health and environmental information.

\section{Methods}

\section{European Respiratory Community Health Survey I}

ECRHS I collected information on symptoms and exposure to known or suspected risk factors for asthma from representative samples of the population living in the participating centres. ECRHS I has been described in detail elsewhere [26, 27]. A random sample of 1,500 males and 1,500 females aged between 20-44 yrs was selected from appropriate local sampling frames. Each participant was sent a brief questionnaire asking about respiratory symptoms (stage 1), and from those who responded, a random sample of 300 males and 300 females was selected to undergo a more detailed clinical examination (stage 2). This included: an extended interviewer-administered questionnaire; blood tests for total immunoglobulin (Ig)E and specific IgE to house dust mite, grass, cat and Cladosporium; assessment of FEV1 and forced vital capacity (FVC); and measurement of bronchial reactivity to methacholine. Participants who were unable to attend the testing centre were visited at home to have the questionnaire administered or were asked the questionnaire over the telephone. If they refused to answer the questionnaire, an attempt was made to ascertain their smoking status. In addition to the random sample, a "symptomatic sample" was also studied, which comprised of participants who had not been selected from the random sample for the clinic assessment but who had reported symptoms of "waking with shortness of breath in the last 12 months", "asthma attack in the last 12 months" or "taking asthma medication". This symptomatic sample was invited to the testing centre to undergo the same tests as those that were performed on the random sample. In most centres, participants were asked to provide "named contacts": contact details of friends and family likely to know their whereabouts should they move house over the next $10 \mathrm{yrs}$.

Response rates across centres varied for each stage of the study but adjustment for nonresponse in estimating the prevalence of symptoms, sensitisation and bronchial reactivity suggested that those who were studied were representative of the populations sampled [4, 28, 29].

\section{European Respiratory Community Health Survey II}

The sample. The cohort of subjects to be studied were defined as all subjects who completed stage 1 of ECRHS I and who, having been selected for stage 2, had at least their smoking status recorded. The number of subjects fulfilling these criteria in each centre is given in table 1 . Figures 1 and 2 show the sample in the form of a flow chart. 
Table 1. - Number of eligible participants per centre in the European Community Respiratory Health Survey (ECRHS) II as defined by number of responders to stage 2 of ECRHS I

\begin{tabular}{|c|c|c|c|c|}
\hline Country & Centre & $\begin{array}{l}\text { Eligible participants } \\
\text { from random } \\
\text { sample }\end{array}$ & $\begin{array}{l}\text { Eligible participants } \\
\text { from symptomatic } \\
\text { sample }\end{array}$ & $\begin{array}{l}\text { Total eligible } \\
\text { participants }\end{array}$ \\
\hline Iceland & Reykjavik & 564 & 84 & 648 \\
\hline \multirow{3}{*}{ Sweden } & Ümea & 552 & 156 & 708 \\
\hline & Uppsala & 622 & 201 & 823 \\
\hline & Goteborg & 682 & 184 & 866 \\
\hline Estonia & Tartu & 431 & 127 & 558 \\
\hline Norway & Bergen* & 835 & 0 & 835 \\
\hline \multirow[t]{2}{*}{ UK } & Norwich & 473 & 108 & 581 \\
\hline & Ipswich & 448 & 111 & 559 \\
\hline \multirow[t]{2}{*}{ Germany } & Hamburg*,\# & 1252 & 0 & 1252 \\
\hline & Erfurt* & 731 & 0 & 731 \\
\hline \multirow[t]{3}{*}{ The Netherlands } & Groningen*, & 380 & 0 & 380 \\
\hline & Geleen* & 415 & 0 & 415 \\
\hline & Bergen-op-zoom* & 452 & 0 & 452 \\
\hline \multirow[t]{2}{*}{ Belgium } & Antwerp City & 564 & 87 & 651 \\
\hline & South Antwerp & 558 & 76 & 634 \\
\hline Switzerland & Basel & 853 & 149 & 1002 \\
\hline \multirow[t]{4}{*}{ France } & Paris* & 652 & 0 & 652 \\
\hline & Bordeaux ${ }^{*, \#}$ & 544 & 0 & 544 \\
\hline & Grenoble & 473 & 49 & 522 \\
\hline & Montpellier*,\# & 456 & 0 & 456 \\
\hline \multirow[t]{5}{*}{ Spain } & Oviedo & 357 & 167 & 524 \\
\hline & Galdakao & 486 & 106 & 592 \\
\hline & Barcelona & 393 & 123 & 516 \\
\hline & Albacete & 435 & 191 & 626 \\
\hline & Huelva & 271 & 132 & 403 \\
\hline \multirow[t]{3}{*}{ Italy } & Verona & 340 & 18 & 358 \\
\hline & Pavia* & 310 & 0 & 310 \\
\hline & Turin & 244 & 111 & 355 \\
\hline USA & Portland ${ }^{\#}$ & 723 & 116 & 839 \\
\hline Australia & Melbourne & 669 & 207 & 876 \\
\hline Total & & 16165 & 2503 & 18668 \\
\hline
\end{tabular}

*: centres who, due to limited resources, only studied a representative sample of responders to stage 1 and therefore have no "symptomatic sample"; " : non-European Union funded centres taking part at their own expense; ": at the time of writing this paper it was unlikely that this centre would provide data for ECRHS II.

Re-contacting the sample. Appropriate local measures were taken to re-contact the eligible participants. In most centres, a short self-completed questionnaire identical to that used in stage 1 of ECRHS I, was posted to the participant's address recorded in 1991-1993, with an accompanying letter asking them to take part in the study. If no response was obtained and ethical permission was granted, local databases likely to contain information on current address (e.g. population registers, health authority registers, electoral rolls) were examined. In addition, the named contacts identified during ECRHS I, were approached for current contact details of participants.

All participants who were located were invited to a local clinic for further testing. While in the clinic, all subjects underwent a series of assessments.

Questionnaires. All subjects who had not already done so (as part of the tracing), completed a short, self-completed questionnaire identical to that used for stage 1 in ECRHS I. They then underwent an interviewer-administered questionnaire that covered the following areas.
Symptoms and medical history. Respiratory symptoms were assessed using the same questions as in ECRHS I (taken from the bronchial symptoms questions of the International Union Against Tuberculosis and Lung Disease questionnaire [30, 31]), hay fever was assessed using the questions used for the International Study of Asthma and Allergies in Childhood (ISAAC) [32] and questions about eczema were based on the new working definition of eczema [33-35]. Severity of asthma was assessed using questions based on the Global Initiative for Asthma (GINA) guidelines' classification of asthma severity [36].

Smoking and exposure to environmental tobacco smoke. As in ECRHS I, subjects were asked to answer a detailed questionnaire on smoking and additional information was collected on exposure to other people's tobacco smoke at home, in the workplace and in social settings.

Occupation. All occupations held since ECRHS I were recorded and coded using International Standard Classification of Occupations (ISCO)-88 codes [37]. 


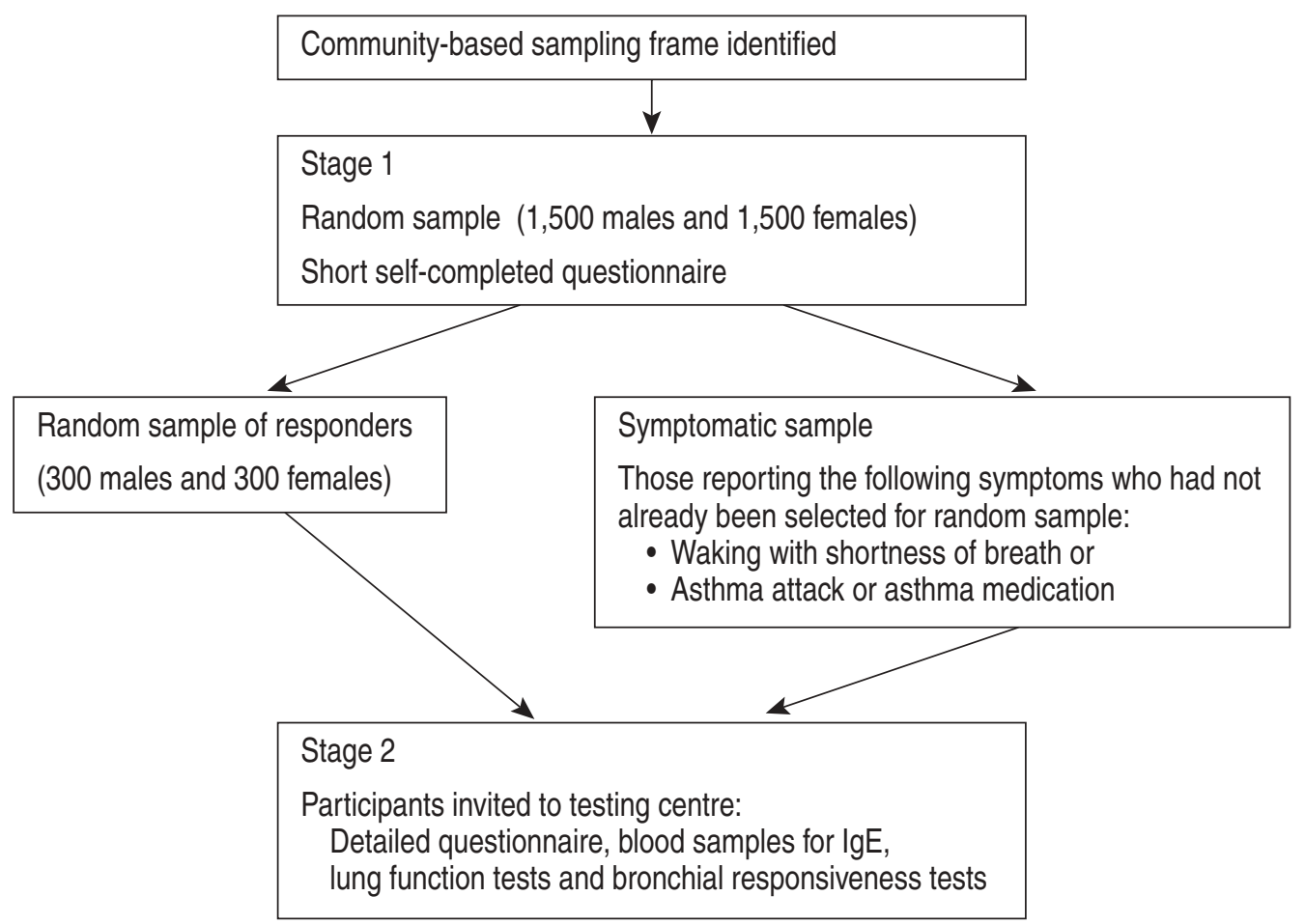

Fig. 1.-Schematic diagram showing the sampling method of the European Community Respiratory Health Survey I (1990-1993). IgE: immunoglobulin E.

In addition, those who reported they had worked as a cleaner, nurse or metal worker were asked to give further details about their workplace activities. Participants who reported that they had been responsible for cleaning and washing in their home,

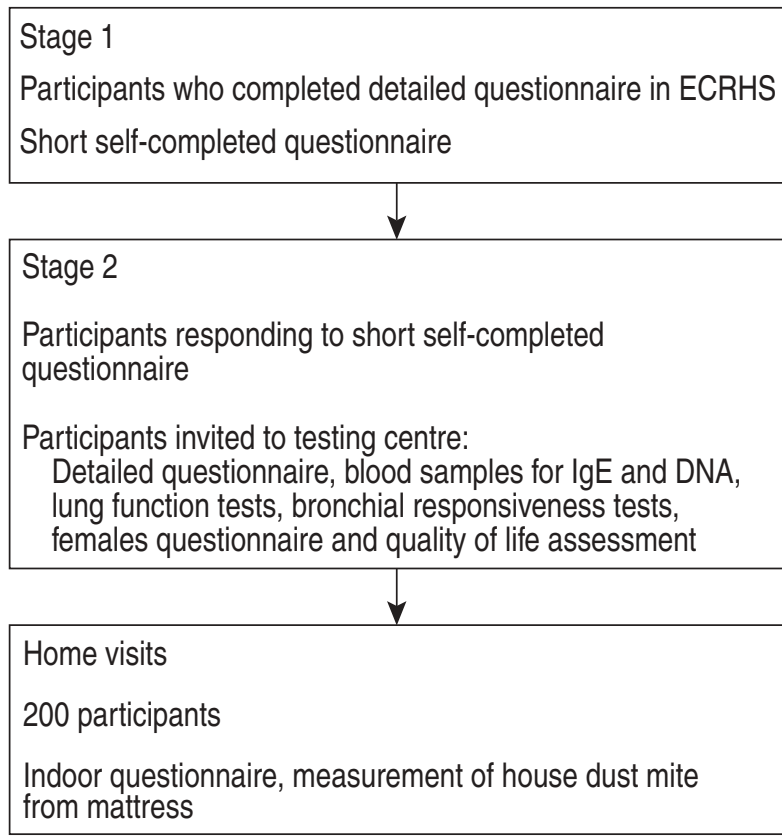

Fig. 2.-Schematic diagram showing the sampling method of the European Community Respiratory Health Survey (ECRHS) II (1999-2002). Follow-up was performed 8-10 yrs after the initial survey. IgE: immunoglobulin E; DNA: deoxyribonucleic acid. had soldered or welded, or had used disinfectants at home or at work since ECRHS I were asked to provide more information on the frequency of these exposures. A Job Exposure Matrix [38] was used to assess occupational exposures since ECRHS I.

Home environment. Information on damp, mould, soft furnishings and exposure to domestic gas appliances was obtained using the same questions as in ECRHS I, with additional information on the frequency of use of gas cookers and ventilation in the kitchen.

Air pollution. All participants were asked to rate their perceived exposure to air pollution using a visual analogue scale developed for the Swiss Study on Air Pollution and Lung Diseases in Adults (SAPALDIA) [39].

Medication and use of services. Use of inhaled and oral drugs for the treatment of breathing problems was recorded using the same questions as in ECRHS I but with further details of dosage and frequency. In particular, there was detailed assessment of the use of steroid inhalers during the followup period.

Information on menstrual history, use of oral contraceptives and use of hormone replacement therapy since the last survey was collected from females only, using a questionnaire devised specifically for this survey.

In most centres, participants were asked to complete the short form (SF)-36, a generic quality of life measure [40], and those with asthma were asked to complete the Juniper Asthma Quality of Life 
Questionnaire [41], a disease-specific quality of life questionnaire.

Blood samples. Blood samples were collected for the measurement of serum-specific IgE and total IgE using the Pharmacia CAP System (Pharmacia Diagnostics, Uppsala, Sweden). Serum samples were stored at $-20^{\circ} \mathrm{C}$ and then transferred to a centralised laboratory where they were tested for specific IgE to house dust mite, grass, cat, Cladosporium and total $\mathrm{IgE}$ using the same method as in ECRHS I.

Lung function testing. Wherever practically possible, baseline lung function measures (FEV1 and FVC) were taken using the same equipment as ECRHS I. In the majority of centres this was a water-sealed bell spirometer (Biomedin, Padova, Italy). Lung function measures were performed in the sitting position with nose clips on and all subjects made at least five forced expiratory manoeuvres. All manoeuvres deemed technically satisfactory were recorded and, if less than two of the five were considered technically satisfactory, the participant was allowed up to four further attempts. If after nine attempts two technically satisfactory manoeuvres had not been made, lung function testing was abandoned.

Bronchial responsiveness. In ECRHS I, centres were required to choose one of two dosing schedules for BR testing to methacholine (Provocholine $\mathbb{R}$, Methapharm Inc., ON, Canada). The same method as used in the higher dosing schedule for ECRHS I was adopted for ECRHS II. First, participants were asked to inhale a vapour of the diluent used to manufacture the methacholine solutions, the vapour being generated by a jet nebuliser (Mefar, SRL, Bovezzo, BS, Italy) set at an inhalation time of $1 \mathrm{~s}$. Depending on whether an individual reported symptoms in the long questionnaire or not, doubling (for those with symptoms) or quadrupling (for those without symptoms) doses of methacholine were then inhaled until a $20 \%$ fall in postdiluent FEV1 was observed or the maximum cumulative dose of $2 \mathrm{mg}$ was reached.

Samples for genetics. Blood samples were collected into $3-10 \mathrm{~mL}$ ethylenediamine tetraacetic acid (EDTA) tubes and frozen at each centre before transportation to a centralised laboratory. Samples were then stored at $-80^{\circ} \mathrm{C}$ until DNA was extracted using a commercially available kit (Puregene, Gentra Inc., MN, USA). Following extraction, genomic DNA was tested using agarose gels and a test polymerase chain reaction (PCR) was run with a tumour necrosis factor (TNF)- $\alpha$ polymorphism. DNA was quantified with the pico green double-stranded (ds) DNA reagent (Molecular Probes, OR, USA). Finally, DNA was distributed into 96-well master plates and adjusted to $300 \mu \mathrm{g} \cdot \mathrm{mL}^{-1}$ before being stored at $-20^{\circ} \mathrm{C}$ for further analyses.

Historical air pollution data. Historical air pollution data were collected to provide information on pollution levels over the follow-up period and to describe changes over time and variations across Europe. In collaboration with experts from the World
Health Organization (WHO), European Centre for Environment and Health, Bilthoven/Bonn, questionnaires were sent to staff working in government and local air quality monitoring agencies. The questionnaire requested all relevant information on local air quality obtained since ECRHS I, with specific reference to arithmetic annual means and annual 95th or 98th percentiles for eight commonly measured pollutants, if they were available. Descriptive information regarding the location of the monitor(s) and the quality control level, according to international criteria, was also asked for. From this, cities were ranked by air pollution levels.

Assessment of particles with a 50\% cut-off aerodynamic diameter of $2.5 \mu \mathrm{m}$. A programme monitoring particles with a 50\% cut-off aerodynamic diameter of $2.5 \mu \mathrm{m}$ (PM2.5) was carried out using a PM2.5 impactor for outdoor use (EPA Wins f/PQ167; BGI, MA, USA). The same equipment has previously been used in the European exposure study Air Pollution Exposure Distribution within Adult Urban Populations in Europe (EXPOLIS) [42]. Every month for a year, each centre collected six samples on 7 days, over a 2week measuring period. A monitor installed within the original sampling area was used, resulting in a total of 84 days (72 filters) per centre to derive an annual mean. Details of this protocol will be presented elsewhere but, in summary, a standardised protocol was developed, predominantly by study partners of the University of Basel (Basel, Switzerland), who were responsible for pre- and postweighing all Teflon filters in a centralised laboratory. The PM2.5 filters were then analysed for selected chemical elements using X-ray spectrometry by the same research team [43].

Indoor environmental assessment. In each centre, 200 homes were visited for direct visual assessment of indoor characteristics, such as type of flooring and presence of double glazing, heating appliances and damp. In addition, a sample of dust was taken from the participant's mattress. An ALK dust collection filter (ALK-Abello, Horsholm, Denmark) was attached to an Electrolux "Mondo" vacuum cleaner (1,300 W) and an area of $1 \mathrm{~m}^{2}$ was vacuumed for a period of $2 \mathrm{~min}$. Dust samples were sealed in a plastic bag, frozen for $24 \mathrm{~h}$ at $-20^{\circ} \mathrm{C}$ and then stored at room temperature, together with a silica gel desiccant. All samples were then forwarded to a central laboratory for analysis of house dust-mite allergen, using a standardised method [44].

Quality control procedures. In all centres, at least one researcher involved in ECRHS II had also worked as part of the study team of ECRHS I. Local training of fieldworkers, using the local language, was conducted using a standardised protocol for questionnaire and health assessment. In most cases fieldworkers from more than one centre, but within the same language group, were trained alongside each other. Adherence to the protocol was assessed through a quality control visit by a member of the coordinating centre to at least one centre in each region, with subsequent visits being conducted by a nominated member of this centre to 
other centres in the region. Where deviations from the protocol were observed they were rectified to ensure standardisation across the study.

The statistical method adopted by ECRHS I for analysing BR, to a large extent, takes account of variation in performance of the equipment used for delivery of methacholine vapour [45]. However, nebulisers used in the study were first calibrated in Melbourne (Australia) [46] to ensure that they all had similar aerosol output. In addition, monthly checks of the pressure of the Mefar dosimeter were carried out in each centre.

As well as the central quality control initiatives, each centre and region adopted appropriate local and regional strategies for maintaining high-quality data and standardisation. For example, in Spain, interviewer technique was assessed by recording one out of 10 interviews in all five participating centres. Tapes were then reviewed by staff in one centre to check for standardisation and good interviewer technique.

Training workshops for both indoor environmental assessment and PM2.5 assessment were held in all centres. For the indoor protocol, a video demonstrating the method of collection of dust samples was developed and distributed to all centres. For PM2.5 assessment, there was a 1-day workshop where staff were shown how to set-up and maintain equipment. Further quality control procedures were carried out for this part of the protocol, including copying downloads of pump performance to the outdoor pollution centre following completion of measures, site visits and remote quality control strategies.

Power calculations. At the outset of ECRHS II, it was envisaged that at least 25 centres would take part, the coordination being funded through a large grant from the European Commission (European Union (EU) funded centres). However, other centres, some outside Europe and others who only later decided to take part, will also provide data for most components of the study (non-EU funded centres) (see table 1).

The power calculations made at the outset of the study for the EU funded centres are given below, but the overall increase in the number of centres included in the study has enhanced the power of the study since these calculations were made.

To compare incidence of wheeze in atopic and nonatopics. It was estimated that ECRHS II would include $\sim 4,364$ individuals with no atopy and no wheeze when studied in ECRHS I and 1,688 with atopy and no wheeze. With a significance level of $5 \%$ the study has $80 \%$ power to detect a significant difference if $2.5 \%$ of nonatopics and $4 \%$ of atopics develop wheeze over the period of follow-up. The power increases to $81 \%$ if $5 \%$ of nonatopics and $7 \%$ of atopics develop wheeze and to $89 \%$ if $10 \%$ of nonatopics and $13 \%$ of atopics develop wheeze.

To compare lung function decline between centres. On average, the number of people seen in each centre for a second measurement of FEV1 is 340 with an average follow-up of 8 yrs. The SD of decline in FEV 1 over 1 yr is $150 \mathrm{~mL}$. With a $5 \%$ significance level and $80 \%$ power, the detectable difference in lung function decline between two centres is $32.3 \mathrm{~mL}$ (equivalent to $4 \mathrm{~mL} \cdot \mathrm{yr}^{-1}$ ).

\section{Progress so far}

Twenty-five European centres in 12 countries organised into 20 research teams were included within a large application for funding. However, five other centres that took part in ECRHS I have taken part in the ECRHS II health examination (but not in the PM2.5 monitoring or the indoor assessment) at their own expense and others may follow.

At the time of writing this paper, a total of 26 centres had at least begun stage 1 of the study (short questionnaire) and 24 had at least begun stage 2 (more extensive phase of investigation). More than 12,000 individuals had completed the short questionnaire, $\sim 9,000$ participants had completed the more extended questionnaire and $\sim 3,500$ participants had had a home visit where a dust sample was taken from their mattress.

\section{Organisational structure}

\section{Study management}

The study is managed through a single Steering Committee and several Working Groups (Outdoor Air Pollution, Occupation, Indoor Environment, Gender, Genetics, Early Life, Quality of Life, Therapy and Economics and Diet). The Chair(s) of each Working Group were automatically a member of the Steering Committee and other researchers were invited to become members as appropriate. Working Groups, comprising both junior and senior researchers directly involved in the project, were responsible for protocol development to ensure collection of information pertinent to their specific area and, over the following years, will be responsible for the analysis and publication of results within their area. The integration of the large number of researchers, research teams and Working Groups is facilitated through the Coordinating Centre of the study, which also acts as a central resource for all queries from participating centres, facilitates the financial management of the study and develops the website for dissemination of the study [47].

\footnotetext{
The European Community Respiratory Health Survey II was prepared by: D. Jarvis (King's College London, London, UK), J. Knox (King's College London), P. Burney (King's College London), S. Chinn (King's College London), C. Luczynska (King's College London), J.M. Antó (Institut Municipal d'Investigació Mèdica, Universitat Pompeu Fabra (IMIM-UPF), Barcelona, Spain), I. Cerveri (University of Pavia, Pavia, Italy), R. de Marco (University of Verona, Verona, Italy), T. Gislasson (University of Iceland,
} 
Reykjavik, Iceland), J. Heinrich (GSF National Research Centre for Environment and Health, Munich, Germany), C. Janson (University of Uppsala, Uppsala, Sweden), N. Kuenzli (University of Basel, Basel, Switzerland), B.Leynaert (Institut National de la Santé et de la Recherche Médicale (INSERM), Paris, France), F. Neukirch (INSERM), J. Schouten (University of Groningen, Groningen, the Netherlands), J. Sunyer (IMIM-UPF), C. Svanes (University of Bergen, Bergen, Norway), P. Vermeire (University of Antwerp, Antwerp, Belgium), M. Wjst (GSF National Research Centre for Environment and Health). Coordinating centre. Project Leader.

P. Burney; Statistician: S. Chinn; Principal Investigator: D. Jarvis; Project Coordinator: J. Knox; Principal Investigator: C. Luczynska; Assistant Statistician: J. Potts.

Steering Committee. J.M. Antó, P. Burney,

I. Cerveri, S.Chinn, R. de Marco, T. Gislason,

J. Heinrich, C. Janson, D. Jarvis, J. Knox,

N. Kuenzli, B. Leynaert, C. Luczynska,

F. Neukirch, J. Schouten, J. Sunyer, C. Svanes, P. Vermeire, M. Wjst.

List of Principal Investigators and Senior Scientific Team. South Antwerp and Antwerp City, Belgium: P. Vermeire, J. Weyler, M. Van Sprundel, V. Nelen. Tartu, Estonia: R. Jogi, A. Soon. Paris, France: F. Neukirch, B. Leynaert, R. Liard, M. Zureik. Grenoble, France: I. Pin, J. Ferran-Quentin. Erfurt, Germany: J. Heinrich, M. Wjst, C. Frye, I. Meyer. Reykjavik, Iceland: T. Gislason, E. Bjornsson, D. Gislason, T. Blondal,

A. Karlsdottir. Turin, Italy: M. Bugiani, P. Piccioni, E. Caria, A. Carosso, E. Migliore, G. Castiglioni. Verona, Italy: R. de Marco, G. Verlato, E. Zanolin, S. Accordini, A. Poli, V. Lo Cascio, M. Ferrari. Pavia, Italy. A. Marinoni, S. Villani, M. Ponzio. Groningen and Geleen, the Netherlands: J. Schouten, M. Kerkhof. Bergen, Norway: A. Gulsvik, E. Omenaas, C. Svanes, B. Laerum. Barcelona, Spain: J.M. Antó, J. Sunyer, M. Kogevinas, J.P. Zock, X. Basagana, A. Jaen, F. Burgos. Huelva, Spain: J. Maldonado, A. Pereira, J.L. Sanchez. Albacete, Spain: J. MartinezMoratalla Rovira, E. Almar. Galdakao, Spain: N. Muniozguren, I. Urritia. Oviedo, Spain: F. Payo. Uppsala, Sweden: C. Janson, G. Boman, D. Norback, M. Gunnbjornsdottir. Goteborg, Sweden: K. Toren, L. Lillienberg, A.C. Olin, B. Balder, A. Pfeifer-Nilsson, R. Sundberg. Umea, Sweden: E. Norrman, M. Soderberg, K. Franklin, B. Lundback, B. Forsberg, L. Nystrom. Basel, Switzerland: N. Kuenzli, B. Dibbert, M. Hazenkamp, M. Brutsche, U. Ackermann-Liebrich. Norwich, $U K$ : D. Jarvis, B. Harrison. Ipswich, UK: D. Jarvis, R. Hall, D. Seaton.

Centres taking part at their own expense. Melbourne, Australia: M. Abramson, R. Woods, E.H. Walters, F. Thien. Bordeaux, France: A. Taytard, C. Raherison. Montpellier, France: J. Bousquet, P. Demoly. Hamburg, Germany: K. Richter. Portland, USA: M. Osborne, S Buist, W. Vollmer, L. Johnson.

Funders. The coordination of this work was supported by the European Commission, as part of their Quality of Life programme, who also funded the indoor environmental assessment and some of the costs of the particulate monitoring equipment (grant code: QLK4-CT-1999-01237). The rest of the Air
Pollution protocol was funded through Swiss Federal Agency for Education and Science. The following bodies funded the local studies. Albacete: Fondo de Investigaciones Santarias (FIS) (grant code: 97/0035-01, 99/0034-01 and 99/0034-02), Hospital Universitario de Albacete, Consejeria de Sanidad. Antwerp: FWO (Fund for Scientific Research)-Flanders Belgium (grant code: G.0402.00), University of Antwerp, Flemish Health Ministry. Barcelona: SEPAR, Public Health Service (grant code: R01 HL62633-01), FIS (grant code: 97/0035-01, 99/0034-01 and 99/ 0034-02) CIRIT (grant code: 1999SGR 00241)). Basel: Swiss National Science Foundation, Swiss Federal Office for Education and Science, Swiss National Accident Insurance Fund (SUVA). Bergen: Norwegian Research Council, Norwegian Asthma and Allergy Association (NAAF), Glaxo Wellcome AS, Norway Research Fund. Bordeaux: Institut Pneumologique d'Aquitaine. Erfurt: GSF-National Research Centre for Environment and Health, Deutsche Forschungsgemeinschaft (DFG). Galdakao: Basque Health Dept. Goteborg: Swedish Heart Lung Foundation, Swedish Foundation for Health Care Sciences and Allergy Research, Swedish Asthma and Allergy Foundation, Swedish Cancer and Allergy Foundation. Grenoble: Programme Hospitalier de Recherche Clinique-DRC de Grenoble 2000 no. 2610, Ministry of Health, Direction de la Recherche Clinique, Ministere de l'Emploi et de la Solidarité, Direction Generale de la Sante, CHU de Grenoble, Comite des Maladies Respiratoires de 1'Isere. Hamburg: GSF-National Reasearch Centre for Environment and Health, DFG. Ipswich and Norwich: National Asthma Campaign. Huelva: FIS (grant code: 97/0035-01, 99/0034-01 and 99/0034-02). Melbourne: National Health and Medical Research Council of Australia. Montpellier: Programme Hospitalier de Recherche Clinique-DRC de Grenoble 2000 no. 2610, Ministry of Health, Direction de la Recherche Clinique, CHU de Grenoble, Ministere de 1'Emploi et de la Solidarite, Direction Generale de la Santé, Aventis, Direction Régionale des Affaires Sanitaires et Sociales Languedoc-Roussillon. Oviedo: FIS (grant code: 97/0035-01, 99/0034-01 and 99/003402). Paris: Ministere de l'Emploi et de la Solidarite, Direction Generale de la Sante, UCB-Pharma, Aventis, Glaxo France, Programme Hospitalier de Recherche CliniqueDRC de Grenoble 2000 no. 2610, Ministry of Health, Direction de la Recherche Clinique, CHU de Grenoble. Pavia: GlaxoSmithKline Italy, Italian Ministry of University and Scientific and Technological Research (MURST), Local University Funding for Research 1998 and 1999. Portland: American Lung Association of Oregon, Northwest Health Foundation, Collins Foundation, Merck Pharmaceutical. Reykjavik: Icelandic Research Council, Icelandic University Hospital Fund. Tartu: Estonian Science Foundation. Turin: ASL 4 Regione Piemonte, AO CTO/ICORMA Regione Piemonte, Ministero dell'Università e della Ricerca Scientifica, Glaxo Wellcome spa. Umeå: Swedish Heart Lung Foundation, Swedish Foundation for Health Care Sciences and Allergy Research, Swedish Asthma and Allergy Foundation, Swedish Cancer and Allergy Foundation. Uppsala: Swedish Heart Lung Foundation, Swedish Foundation for Health Care Sciences and Allergy Research, Swedish Asthma and Allergy Foundation, Swedish 
Cancer and Allergy Foundation. Verona: University of Verona, MURST, GlaxoSmithKline Italy.

Laboratories. Blood samples were analysed for immunoglobulin $\mathrm{E}$ and dust samples were analysed for house dust-mite allergen at King's College London. Extraction of deoxyribonucleic acid was carried out at the University of Munich, Germany. The analyses of particles with a 50\% cut-off aerodynamic diameter of $2.5 \mu \mathrm{m}$ were carried out at the University of Basel.

\section{References}

1. Yunginger JW, Reed CE, $\mathrm{O}^{\prime}$ Connell EJ, Melton LJ, $\mathrm{O}^{\prime}$ Fallon WM, Silverstein MD. A community-based study of the epidemiology of asthma. Incidence rates, 1964-1983. Am Rev Respir Dis 1992; 146: 888-894.

2. Dodge R, Burrows B. The prevalence and incidence of asthma and asthma-like symptoms in a general population sample. Am Rev Respir Dis 1980; 122: $567-575$.

3. Strachan DP, Butland B, Anderson HR, Butland BK. Incidence and prognosis of asthma and wheezing illness from early childhood to age 33 in a national British birth cohort. BMJ 1996; 312: 1195-1199.

4. European Community Respiratory Health Survey. Variations in the prevalence of respiratory symptoms, self-reported asthma attacks, and use of asthma medication in the European Community Respiratory Health Survey (ECRHS). Eur Respir J 1996; 9: 687-695.

5. Settipane R, Hagy GW, Settipane GA. Long term risk factors for developing asthma and allergic rhinitis; a 23 year follow up of college students. Allergy Proc 1994; 15: 21-25.

6. Ohman JL, Sparrow D, MacDonald MR. New onset wheezing in an older male population: Evidence of allergen sensitization in a longitudinal study. J Allergy Clin Immunol 1993; 91: 752-757.

7. Troisi RJ, Speizer FE, Willett WC, Trichopoulos D, Rosner B. Menopause, postmenopausal estrogen preparations, and the risk of adult-onset asthma. A prospective cohort study. Am J Respir Crit Care Med 1995; 152: 1183-1188.

8. Hendrick DJ. The world wide problem of occupational asthma. Clin Exp Allergy 2001; 31: 1-4.

9. Sparrow D, O'Connor G, Basner R, Rosner B, Weiss $\mathrm{S}$. Predictors of the new onset of wheezing among middle-aged and older men. Am Rev Respir Dis 1993; 147: 367-371.

10. Troisi RJ, Speizer FE, Rosner B, Trichopoulos D, Willett WC. Cigarette smoking and incidence of chronic bronchitis and asthma in women. Chest 1995; 108: 1557-1561.

11. Barbee RA, Kaltenborn W, Lebowitz MD, Burrows B. Longitudinal changes in allergen skin test reactivity in a community population sample. J Allergy Clin Immunol 1987; 79: 16-24.

12. Panhuysen CI, Vonk JM, Koeter GH, et al. Adult patients may outgrow their asthma: a 25-year followup study. Am J Respir Crit Care Med 1997; 155: 12671272.

13. Rodriguez B, Masaki K, Burchfiel C, et al. Pulmonary function decline and 17-year total mortality: The
Honolulu Heart Programme. Am J Epidemiol 1994; 140: 398-408.

14. Ryan GF, Knuiman MW, Divitini ML, James A, Musk AW, Bartholomew HC. Decline in lung function and mortality: The Busselton Health Study. J Epidemol Comm Health 1999; 53: 230-234.

15. Tockman MS, Pearson JD, Fleg JL, et al. Rapid decline in FEV1. A new risk factor for coronary heart disease mortality. Am J Respir Crit Care Med 1995; 151: 390-398.

16. Roca J, Burgos F, Sunyer J, et al. Reference values for forced spirometry. Eur Respir J 1998; 11: 1354 1362.

17. Rijcken B, Schouten JP, Xu X, Rosner B, Weiss S. Airway hyper-responsiveness to histamine associated with accelerated decline in FEV1. Am J Respir Crit Care Med 1995; 151: 1377-1382.

18. Gottlieb DJ, Sparrow D, O'Connor GT, Weiss ST. Skin test reactivity to common aeroallergens and decline of lung function. The Normative Aging Study. Am J Respir Crit Care Med 1996; 153: 561-566.

19. Tracey M, Villar A, Dow L, Coggon D, Lampe F, Holgate ST. The influence of increased bronchial responsivenss, atopy, and serum $\mathrm{IgE}$ on decline in FEV1. Am J Respir Crit Care Med 1995; 151: 656662.

20. Weiss S, O'Connor G, DeMolles D, Platts-Mills T, Sparrow D. Indoor allergens and longitudinal FEV1 decline in older adults: The Normative aging Study. J Allergy Clin Immunol 1998; 101: 720-725.

21. Abbey DE, Burchette RJ, Knutsen SF, McDonnell WF, Lebowitz MD, Enright PL. Long-term particulate and other air pollutions and lung function in non-smokers. Am J Respir Crit Care Med 1998; 158: 289-298.

22. Peters JM, Avol E, Gauderman WJ, et al. A study of twelve Southern California communities with differing levels and types of air pollution. II. Effects on pulmonary function. Am J Respir Crit Care Med 1999; 159: 768-775.

23. Adams NP, Bestall J, Jones PW. Inhaled beclomethasone versus placebo (Cochrane Review). Update Software. Oxford, The Cochrane Library, 2001.

24. Adams NP, Bestall J, Jones PW. Inhaled beclomethasone at different doses for long term asthma (Cochrane Review). Update Software. Oxford, The Cochrane Library, 2001.

25. Van Schayck CP, Dompeling E, Van Herwaarden CL, Wever AM, Van Weel C. Interacting effects of atopy and bronchial hyperresponsiveness on the annual decline in lung function and the exacerbation rate in asthma. Am Rev Respir Dis 1991; 144: 1297-1301.

26. Burney P, Luczynska C, Chinn S, Jarvis D. The European Community Respiratory Health Survey. Eur Respir J 1994; 7: 954-960.

27. Janson C, Anto JM, Burney P, et al. The ECRHS: what are the main results so far? Eur Respir J 2001; 18: 598-611.

28. European Community Respiratory Health Survey. Variation in bronchial responsiveness in the European Community Respiratory Health Survey. Eur Respir $J$ 1997; 10: 2495-2501.

29. Burney P, Malmberg E, Chinn S, Jarvis D, Luczynska CM, Lai E. The distribution of total and specific serum IgE in the European Community Respiratory Health Survey. J Allergy Clin Immunol 1997; 99: 314-322.

30. Burney P, Chinn S. Developing a new questionnaire 
for measuring the prevalence and distribution of asthma. Chest 1987; 91: 79S-83S.

31. Abramson MJ, Hensley MJ, Saunders NA, Wlodarczyk JH. Evaluation of a new asthma questionnaire. J Asthma 1991; 28: 129-139.

32. Asher MI, Keil U, Anderson HR, et al. International Study of Asthma and Allergies in Childhood (ISAAC): rationale and methods. Eur Respir J 1995; 8: 483-491.

33. Williams HC, Burney P, Pembroke AC, Hay RJ. The U.K. Working Party's Diagnostic Criteria for Atopic Dermatitis. III. Independent hospital validation. $\mathrm{Br}$ J Dermatol 1994; 131: 406-416.

34. Williams HC, Burney P, Strachan D, Hay RJ. The U.K. Working Party's Diagnostic Criteria for Atopic Dermatitis. II. Observer variation of clinical diagnosis and signs of atopic dermatitis. Br J Dermatol 1994; 131: 397-405.

35. Williams HC, Burney P, Hay RJ, et al. The U.K. Working Party's Diagnostic Criteria for Atopic Dermatitis. I. Derivation of a minimum set of discriminators for atopic dermatitis. $\mathrm{Br} \mathrm{J}$ Dermatol 1994; 131: 383-396.

36. National Heart LaBI. Global Initiative for Asthma. Global strategy for asthma management and prevention. Bethesda, National Institutes of Health, 1995.

37. International Labour Office. International Standard Classification of Occupations (ISCO-88). Geneva, Geneva: International Labour Office, 1990.

38. Kennedy SM, Le Moual N, Choudat D, Kauffmann F. Development of an asthma specific job exposure matrix and its application in the epidemiological study of genetics and environment in asthma (EGEA). Occup Env Med 2000; 57: 635-641.

39. Oglesby L, Kunzli N, Monn C, Schindler C,
Ackermann-Liebrich U, Leuenberger P. Validity of annoyance scores for estimation of long term air pollution exposure in epidemiologic studies: the Swiss Study on Air Pollution and Lung Diseases in Adults (SAPALDIA). Am J Epidemiol 2000; 152: 75-83.

40. Ware JE, Kosinski M, Keller SD. SF-36 Physical and Mental Health Summary Scales: a User Manual. Boston, MA, The Health Institute, New England Medical Centre, 1994.

41. Juniper EF, Guyatt GH, Ferrie PJ, Griffith LE. Measuring quality of life in asthma. Am Rev Respir Dis 1993; 147: 832-838.

42. Jantunen M, Haenninen O, Katsouyanni K, et al. Air pollution exposure in European cities; The EXPOLIS Study. J Exp Anal Environ Epidemiol 1998; 8: 495-518.

43. Mathys P, Stern W, Oglesby L, et al. Elemental analysis of airborne particulate matter by ED-XRF within the European EXPOLIS Study. ICP Information Newsletter 27(3), 2001.

44. Luczynska C, Arruda LK, Platts-Mills TAE, Miller JD, Lopez M, Chapman MD. A two-site monoclonal antibody ELISA for the quantification of the major Dermatophagoides spp. allergens, Der $p$ I and Der $f 1$. J Immunol Methods 1989; 118: 227-235.

45. Chinn S, Arossa W, Jarvis D, Luczynska CM, Burney $P$. Variation in nebulizer output and weight output from the Mefar dosimeter: implications for multicentre studies. Eur Respir J 1997; 10: 452-456.

46. Dennis JH, Stenton SC, Beach JR, Avery AJ, Walters EH, Hendrick DJ. Jet and ultrasonic nebuliser output: use of a new method for direct measurement of aerosol output. Thorax 1990; 45: 728-732.

47. European Community Respiratory Health Survey. www.ecrhs.org. Date last updated: 16/02/02. 